\title{
Mecanismos de participação e atuação de grupos de interesse no processo regulatório brasileiro: 0 caso da Agência Nacional de Energia Elétrica (Aneel)
}

\author{
Mariana Batista da Silva \\ Universidade Federal de Pernambuco
}

\begin{abstract}
As agências reguladoras se constituíram como a grande inovação institucional da reforma do Estado brasileiro. De modo a suprir o gap de legitimidade que emerge do fato de que tais agências não são controladas diretamente por nenhum representante eleito, seu desenho institucional foi formulado de modo a propiciar mecanismos de participação social. Entre estes, as audiências públicas se constituem no objeto deste estudo. Pergunta-se: a quais interesses serve esse mecanismo de participação social? De modo a responder tal questionamento, é realizada uma análise institucional do mecanismo e um mapeamento dos participantes e das colaborações enviadas às audiências da Agência Nacional de Energia Elétrica (Aneel) (1998-2006). A análise dos dados indica uma sobrerrepresentação dos interesses dos regulados. Por fim, o estudo indica que as audiências públicas permitem a permeabilidade da ação regulatória aos diversos grupos da sociedade. Entretanto, essa permeabilidade demonstra uma tendência seletiva, podendo se constituir numa via de acesso à captura.

Palavras-chave: agências reguladoras; grupos de interesse; accoutability; audiências públicas.
\end{abstract}

Mecanismos de participación y actuación de grupos de interés en el proceso regulatorio brasileño: el caso de la Agencia Nacional de Energía Eléctrica (Aneel)

Las agencias reguladoras se constituyeron como la gran innovación institucional de la Reforma del Estado brasileño. Con el fin de proporcionar el gap de legitimidad que surge del hecho de que dichas agencias no están controladas directamente por ningún representante elegido, su diseño institucional fue formulado para propiciar mecanismos de participación social. Entre estos, las audiencias públicas se constituyen en el objeto de este estudio. La pregunta es: ¿a cuáles intereses sirve ese mecanismo de participación social? Para responder dicho cuestionamiento, se realiza un análisis institucional del mecanismo y un mapeo de los participantes y de las colaboraciones enviadas a las audiencias de Aneel (1998-2006). El análisis de los datos indica una sobrerrepresentación de los intereses de los participantes sujetos al reglamento. Por fin, el estudio indica que las audiencias públicas permiten la permeabilidad de la acción regulatoria a los diversos grupos de la sociedad. Sin embargo, esa permeabilidad demuestra una tendencia selectiva, pudiendo constituirse en una vía de acceso a la captura.

Artigo recebido em 19 nov. 2010 e aceito em 26 abr. 2011. Agradeço aos membros do Programa de Educação Tutorial da Universidade Federal de Pernambuco (UFPE) pelas discussões e comentários a esse texto. 
Palabras Clave: agencias reguladoras; grupos de interés; accoutability; audiencias públicas.

\begin{abstract}
Mechanisms of participation and performance of interest groups in the Brazilian regulatory process: the case of the National Agency of Electrical Energy (Aneel)

Regulatory agencies have been constituted as the great institutional innovation of the Reform of the Brazilian State. In order to bridge the gap of legitimacy that emerges from the fact that such agencies are not directly controlled by any elected representatives, their institutional design has been formulated so as to provide mechanisms for social participation. Among these, the public hearings constitute the object of this study. We wonder whose interests serve this mechanism of social participation? In order to answer this question, we conducted an analysis of the institutional mechanism and a mapping of participants and audience contributions sent to Agência Nacional de Energia Elétrica (Aneel) (1998-2006). Data analysis indicates an overrepresentation of the interests of the regulated industries. Finally, the study indicates that the public hearings allow the permeability of the regulatory process to the various groups in society. However, this permeability demonstrates a selective trend, and may constitute a pathway for capture.
\end{abstract}

KEY WORDs: regulatory agencies; interest groups; accountability; public hearings.

\title{
1. Introdução
}

A década de 1990 foi marcada pelo início de profundas transformações na estrutura do Estado brasileiro. A reforma do Estado desenvolvida no período, que tinha por base o processo de privatização e as reformas institucionais, elegeu como principal objetivo dotar o Estado de maior flexibilidade e também de uma maior eficiência em sua atuação (Rezende, 2002). Neste contexto de liberalização dos mercados, a reforma regulatória assume papel fundamental ao instituir uma nova arena de tomada de decisão: as agências reguladoras. Construídas com o objetivo de garantir a credibilidade regulatória num contexto de pós-privatização (Mueller e Pereira, 2002), tais agências se constituem na grande inovação institucional da reforma do Estado, inaugurando uma nova forma de relacionamento entre o Poder Executivo, os órgãos reguladores e a sociedade.

Tendo por principal característica a autonomia que apresentam diante dos poderes políticos constituídos, esses novos órgãos regulatórios ganham grande visibilidade devido à complexidade de suas funções, que envolvem imposição de regras, instituição de normas, punição e arbitragem, assumindo papéis executivos, legislativos e judiciários (Nunes, 2001; Nunes et al., 2007). A conjunção desses dois fatores - ausência de controle político direto e amplitude de funções e poderes, que têm impacto direto sobre a imposição de custos e benefícios à atividade econômica (Gerber e Teske, 2000) — tem por resultado um debate acerca da legitimidade da ação de tais órgãos. O questionamento gira em torno do fato de que, mesmo inseridas numa estrutura de accountability horizontal, as agências reguladoras não são controladas diretamente por nenhum representante político ou têm seus diretores eleitos através do voto popular.

Tendo isto em mente, de modo a suprir esse gap de legitimidade, o desenho institucional dessas agências foi formulado de modo a propiciar mecanismos de participação da 
sociedade diretamente na agência, como uma forma de possibilitar a expressão por parte da sociedade de suas demandas específicas à agência reguladora, e também de disseminar informação acerca das ações da agência. Entre os mecanismos que desempenham essa função, podemos citar como principais a ouvidoria, os conselhos consultivos e as audiências e consultas públicas. Entre esses, as audiências públicas ${ }^{1}$ se constituem numa preocupação com o procedimento regulatório, de modo que propiciam a participação no processo decisório da agência, possibilitando a influência direta dos participantes no resultado final através da formulação de contribuições. Deste modo, a partir do relacionamento direto com os grupos da sociedade e da possibilidade de alteração do resultado final da regulação, as audiências públicas passam a se constituir numa arena de ação de interesses da sociedade, e por isto se constituem no objeto desse estudo. Perguntamo-nos: a quem serve esse mecanismo de participação? De modo a responder tal questionamento, realizamos uma análise das audiências públicas da Agência Nacional de Energia Elétrica (Aneel), no período que vai do ano de 1998 - ano de instituição do mecanismo - ao ano de 2006, tendo por foco seus participantes e os documentos enviados como sugestão à matéria em pauta.

A estrutura estabelecida para o desenvolvimento desse trabalho, além desta introdução, está composta de mais cinco seções: na seção seguinte trabalhamos a temática da reforma do Estado e o desenho institucional das agências reguladoras, enfatizando seus principais mecanismos de autonomia e de accountability. Em seguida, apresentamos os principais mecanismos de participação social nas agências nacionais e analisamos a estrutura institucional das audiências públicas da Aneel, nosso objeto de estudo. Na seção posterior, discutimos os principais postulados teóricos e as hipóteses derivadas. Em seguida, apresentamos os resultados alcançados. E, por último, a conclusão.

\section{A reforma do Estado e o desenho institucional das agências reguladoras}

Tema de amplo consenso, os anos de 1990 para o Brasil se constituíram na "década das reformas". O chamado Estado desenvolvimentista, caracterizado pela forte intervenção no mercado, principalmente em setores estratégicos para o desenvolvimento nacional como o petróleo e as telecomunicações, e pela centralização do aparelho do Estado, já começava a mostrar fortes indícios de crise na década de 1980 (Abrúcio, 2005). Assim, "fazer o Estado funcionar melhor e a um menor custo tornou-se a palavra de ordem" (Rezende, 2002:163).

No eixo da constituição dessa nova organização do Estado, colocou-se a privatização das empresas públicas que até então se encarregavam diretamente de prover os bens públicos e distribuí-los, além de ter sua gerência e regulação sob o mesmo órgão. Entre 1991 e 2001,

\footnotetext{
${ }^{1}$ As audiências/consultas públicas podem assumir um papel e ter funções e procedimentos diferentes, podendo a mesma nomenclatura significar mecanismos diferentes. Deste modo, a caracterização de audiências públicas neste momento exposta refere-se ao mecanismo proposto pela Aneel, unidade de análise do presente estudo.
} 
o governo brasileiro privatizou mais de 100 empresas estatais e transferiu para o controle privado participações minoritárias em várias companhias (Anuatti-Neto et al., 2005). Os leilões geraram US\$ 67,9 bilhões em receitas, mais US\$18,1 bilhões em transferências de dívidas aos compradores, constituindo um dos maiores programas de privatização do mundo (AnuattiNeto et al., 2005).

Com a transferência da atividade de provisão dos bens públicos para a iniciativa privada num esforço de diminuir o tamanho do Estado, ao mesmo tempo que fortaleceu seu núcleo central de atividades (Bresser-Pereira, 2005a, 2005b; Presidência da República, 1995), surgiu a necessidade de o Estado supervisionar a produção e a distribuição desses bens, caracterizando a ascensão do "Estado regulador" (Majone, 1999). Com este processo de liberalização e posterior re-regulação sob um novo modelo (Abranches 1999; Melo, 2000), a produção e a regulação são repartidas em duas funções distintas, a produção a cargo da iniciativa privada e a regulação como monopólio do Estado. ${ }^{2}$ Segundo Neto (2002a:73),

[A] necessidade regulatória aumenta porque, deixando o Estado de ser ele próprio provedor dos bens ou serviços de relevância social, tem ele que passar a exercer algum tipo de controle sobre essa atividade, sob pena de estar descurando de controlar a produção de uma utilidade dotada de essencialidade e relevância.

Nesse contexto, são instituídas as agências reguladoras como corolário da transição do modelo endógeno de regulação - centrado na autorregulação por departamentos de ministérios gestores — para o modelo de regulação por agência independente (Melo, 2002). O objetivo declarado desses órgãos é o de garantir o equilíbrio entre as empresas reguladas, os consumidores e o governo, de forma imparcial. Para tanto, as agências reguladoras se inserem no ordenamento jurídico brasileiro como autarquias em regime especial. Isto as caracteriza como órgãos com personalidade jurídica, receita e patrimônio próprios. Não são subordinadas a nenhum órgão do governo, são apenas vinculadas aos ministérios.

Do ponto de vista institucional, as agências reguladoras se constituem como a principal inovação organizacional da reforma do Estado brasileiro. Seu escopo de atuação vai além da implementação de políticas de distribuição ou de redistribuição de renda que competem a uma burocracia comum. Reunindo num só órgão, livre de obrigação direta com qualquer instituição política, a atividade das agências reguladoras envolve os três poderes do Estado, Executivo, Legislativo e Judiciário (Nunes, 2001), na implementação contextualizada de diretrizes básicas que emanam de políticas de Estado e não de políticas de governo.

\footnotetext{
${ }^{2}$ No Brasil, pode ser vista a permanência da iniciativa do Estado mesmo após a privatização, como no setor de energia. Contudo, há uma reorganização, de forma que a gerência do empreendimento econômico não se confunde com a atividade regulatória, sendo as empresas estatais também submetidas ao marco regulatório estabelecido, da mesma forma que a iniciativa privada.
} 
No que concerne à relação das agências com os poderes políticos, o desenho institucional é o de autonomia jurídica e política. ${ }^{3}$ Possuem autonomia decisória para o emprego da expertise regulatória e para cumprir seu objetivo de garantir a credibilidade regulatória, sinalizando para o mercado regras claras, estáveis e longe de ingerências políticas (Mueller e Pereira, 2002; Correa et al., 2006). A autonomia das agências é estabelecida por características institucionais como podemos ver no quadro abaixo:

\section{Quadro 1}

Autonomia das agências reguladoras

\begin{tabular}{|c|}
\hline Mecanismos de Autonomia \\
\hline Autarquia especial sem subordinação hierárquica \\
Mandatos fixos e não coincidentes dos dirigentes \\
Estabilidade dos dirigentes no cargo \\
Autonomia administrativa (última instância de recurso no âmbito administrativo) \\
Orçamento próprio \\
Quadro de pessoal próprio \\
Procedimentos administrativos estabelecidos em lei \\
\hline
\end{tabular}

Fonte: Elaboração própria.

Mecanismos como a estabilidade dos diretores que são efetivados no cargo mediante arguição do Legislativo e possuem mandatos fixos e não coincidentes com o do presidente, orçamento e quadro de pessoal próprios, formalmente, garantem a autonomia decisória, técnica e operacional das agências (Melo, 2002). Também importante para sua autonomia decisória é o mecanismo de autonomia administrativa, que prevê a não intervenção de outras instituições nas normas instituídas pela agência. Por último, seus objetivos e sua forma de intervenção só podem ser modificados mediante legislação, devido à sua não inserção em alguma hierarquia, o que proporciona à agência espaço para regular sob diretrizes gerais estáveis.

O desenho institucional baseado na estabilidade dos dirigentes e independência orçamentária, funcional e gerencial é fruto do objetivo expresso de isolar a atividade regulatória da interferência política. Isto porque os investimentos na área de infraestrutura são sunk costs ${ }^{4}$

\footnotetext{
${ }^{3}$ Vale ressaltar que a análise aqui empreendida se concentra no que é estabelecido e não se estende para a análise empírica da problemática da efetiva autonomia das agências reguladoras. Problemática esta de maior importância e que vem desafiando os estudiosos do tema no Brasil, mas que, contudo, foge ao escopo do trabalho aqui proposto. Cf. Correa et al. (2006); Mueller (2002); Mueller e Pereira (2002); Pacheco (2003).

${ }^{4}$ Sunk costs são investimentos que, uma vez empregados, o seu valor em usos alternativos é substancialmente inferior ao custo (Spiller, 1996:422). Isto significa que o investidor incorre em alto custo fixo no momento de estabelecimento no setor e fica vulnerável a um grande prejuízo em caso de ação oportunista dos governantes, já que não pode facilmente transferir para outra atividade ou rever o valor empregado. Podemos citar como exemplo clássico os setores de saneamento e energia elétrica.
} 
e os investidores veem a relação entre as agências e os poderes políticos como uma chance para os políticos agirem oportunistamente, modificando o marco regulatório de acordo com suas preferências de cunho eleitoral ou de controle inflacionário (Levy e Spiller, 1996; Correa et al., 2006). Entretanto, a autonomia das agências não é exercida livremente de qualquer constrangimento (constraints), como pode ser visto no quadro abaixo:

\section{Quadro 2 \\ Accountability ${ }^{5}$ nas agências reguladoras}

\begin{tabular}{|c|}
\hline Mecanismos de Accountability \\
\hline Legislação de criação da agência (procedimentos) \\
Convocação de diretores para prestação de contas nas comissões legislativas \\
Ouvidoria com mandato \\
Publicidade dos atos e atas de decisão \\
Justificativa por escrito das decisões dos dirigentes \\
Conselho consultivo \\
Audiências/consultas públicas \\
Diretoria colegiada \\
Quarentena dos diretores \\
Contrato de gestão \\
Revisão judicial
\end{tabular}

Fonte: Elaboração própria.

A estrutura institucional das agências também é desenhada de modo a garantir a responsabilização, sendo responsiva aos representantes eleitos por meio, principalmente, da legislação de criação da agência, na qual são definidos os objetivos a serem perseguidos e os procedimentos a serem seguidos (McCubbins, Noll e Weingast, 1987). Além deste, têm-se também mecanismos como o contrato de gestão, o pedido de esclarecimento, as audiências instituídas pelo Legislativo, a indicação e arguição dos diretores da agência, entre outros que proporcionam uma estrutura de accountability horizontal expressiva. A ausência da inserção das agências numa estrutura hierárquica do governo faz surgir o Judiciário como importante ator, já que a este é instituída a prerrogativa de revisar as decisões tomadas pelas agências, caracterizando-se como um importante momento de responsabilização da atividade regulatória. ${ }^{6}$

${ }^{5}$ Os termos accountability e responsabilização serão utilizados indistintamente ao longo do texto.

${ }^{6}$ Sobre o papel do Judiciário na política regulatória, ver trabalho pioneiro de Costa Júnior e Silva (2008). 
Ademais, não apenas o accountability horizontal é enfatizado no desenho das agências, ou seja, a responsabilização da ação regulatória não só se refere apenas aos poderes do Estado, mas também à sociedade. Deste modo, o desenho institucional também contém mecanismos de transparência e prestação de contas, que buscam, ao mesmo tempo, evitar a captura por grupos de interesse e também inserir a política regulatória no contexto social, incentivando a expressão de demandas da sociedade diretamente no processo regulatório. Entre os mecanismos acima citados, a publicidade dos atos e a necessidade de justificativa das decisões têm o objetivo de garantir uma maior transparência e constrangimento sobre os reguladores, impedindo decisões claramente enviesadas e sem justificativa. A diretoria colegiada e a quarentena dos diretores buscam instituir uma maior dificuldade de captura da regulação, impedindo a concentração de poderes e também o incentivo sobre os diretores advindo da possibilidade de trabalhar na empresa regulada assim que entregar o cargo. Além desses mecanismos, a ouvidoria, os conselhos consultivos e as consultas e audiências públicas buscam integrar a sociedade diretamente nas atividades da agência, promovendo uma maior receptividade às demandas dos diversos grupos sociais e também uma maior difusão de informação acerca das ações da agência.

A partir dessa breve análise do desenho institucional das agências reguladoras, pode ser visto que os mecanismos analisados, tanto de autonomia quanto de accountability, orientamse para a disjuntiva distanciamento/aproximação das agências perante a sociedade e aos atores do Estado. Isto quer dizer que as agências reguladoras agem num ambiente no qual duas fontes de pressão podem ser evidenciadas, a política e a econômica/social. A essas duas fontes de pressão correspondem dois focos de análise no âmbito dos estudos sobre regulação: o foco no processo regulatório, ou no como se regula, caracterizado, principalmente, pelos estudos da relação entre os poderes políticos e as agências reguladoras. O segundo foco de análise corresponde ao lado da demanda, ou seja, ao relacionamento da regulação com a sociedade, com os grupos específicos econômicos e sociais.

O presente trabalho tem por base o segundo foco de análise, porém, ressaltando a importância do desenho institucional. Isto é, pretende analisar um padrão específico de relacionamento entre o órgão regulador e a sociedade, a partir de um ponto de vista pouco explorado: a integração da sociedade na atividade regulatória por meio de mecanismos de participação social. Na próxima seção nos deteremos nesse ponto.

\section{Mecanismos de participação: arenas institucionalizadas para ação de interesses}

A atividade regulatória é marcada por uma especificidade que a diferencia dos demais tipos de políticas públicas: sua atividade consiste no estabelecimento de regras que interferem no curso do mercado, isto é, constitui-se na ação direta do poder do Estado para constranger a ação de atores privados, podendo gerar custos ou benefícios concentrados (Gerber e Teske, 2000). "The regulatory decision involves a direct choice as to who will be indulged and who deprived" (Lowi, 1964:691). Deste modo, tendo em mente a importância e a visibilidade que a atividade 
regulatória adquire por interferir na liberdade dos atores privados, a delegação do poder de regular para agências independentes gera um acalorado debate com relação à legitimidade de ação de tais órgãos. No âmbito de um regime democrático, no qual o elemento básico é a eleição da classe responsável pela condução dos assuntos do Estado, qual a legitimidade de um órgão que não tem seus diretores eleitos democraticamente e não é controlado diretamente pelos políticos?

Com o objetivo de diminuir esse gap de legitimidade da atividade regulatória por agências independentes, o seu desenho institucional foi formulado de modo a inserir a sociedade no processo regulatório, através de formas diretas de participação na agência, e não somente indiretamente através dos políticos. Deste modo, instituindo a interação entre agência reguladora e sociedade, os mecanismos de participação se constituem em arenas formais de integração dos interesses da sociedade no âmbito da construção da política regulatória.

A análise preliminar dos mecanismos de participação previstos nas agências reguladoras nacionais brasileiras nos mostra suas principais formas. Contrariamente ao que ocorre no sistema regulatório norte-americano, que possui um regulamento geral acerca dos procedimentos que devem ser seguidos pelas autoridades regulatórias - o Administrative Procedure Act (APA) (Golden, 1998) — , incluindo a previsão de determinados mecanismos de participação padronizados em todos os órgãos regulatórios, no sistema brasileiro não há nenhum tipo de orientação geral formalizada nesse sentido. Contudo, apesar de uma variação no que concerne a quantos mecanismos são adotados e ao seu desenho específico, pode ser observado um número reduzido de formas no âmbito das agências nacionais, como pode ser visto no quadro abaixo:

Quadro 3

Principais mecanismos de participação nas agências reguladoras federais

\begin{tabular}{|c|c|}
\hline Agência & Mecanismo \\
\hline Aneel & ouvidoria; audiências/consultas públicas \\
\hline Anatel & ouvidoria; audiências/consultas públicas; conselho consultivo \\
\hline ANP & audiências/consultas públicas \\
\hline Anvisa & $\begin{array}{c}\text { ouvidoria; audiências/consultas públicas; conselho consultivo; câmaras técnicas; câmaras } \\
\text { setoriais }\end{array}$ \\
\hline ANS & ouvidoria; consultas públicas; câmara de saúde suplementar \\
\hline ANA & audiências públicas \\
\hline Antaq & ouvidoria; audiências públicas \\
\hline ANTT & ouvidoria; audiências/consultas públicas \\
\hline Ancine & ouvidoria; consultas públicas \\
\hline Anac & ouvidoria; conselho consultivo; audiências/consultas públicas \\
\hline
\end{tabular}

Fonte: Elaboração própria a partir da análise das leis de criação de cada agência, regimentos internos e consultas aos sites. 
Como pode ser visto no quadro antes exposto, das 10 agências reguladoras nacionais, todas possuem algum tipo de mecanismo de participação social. Deste modo, pode-se notar que, mesmo na ausência de um regulamento geral que imponha o estabelecimento de tais mecanismos, há um entendimento em torno de sua conveniência. Ademais, a existência desses mecanismos voltados para a integração da sociedade no processo regulatório, sendo vistas, inclusive, agências com vários mecanismos diferentes, pode ser considerada um "avanço democrático" (Mattos, 2007). Isto devido ao fato de que os órgãos integrantes do sistema regulatório pré-reforma do Estado não possuíam nenhum tipo de estrutura nesse sentido, sendo a atividade regulatória insulada no poder Executivo (Mattos, 2007). Nas palavras de Mattos (2007:9):

Before the creation of regulatory agencies, only the president and councils organized inside the ministerial bureaucracy defined public policies in Brazil. (...) In this perspective, before the implementation of state reform in Brazil, it could be argued that just those with access to the president or to ministry's cabinets could influence the process of regulation of economic activities and social life.

De fato, a instituição das agências reguladoras no âmbito da reforma do Estado se constituiu como uma forma de estabelecer, ao menos formalmente, uma maior transparência e responsividade da atividade regulatória à sociedade como um todo. Contudo, para além da constatação desse avanço democrático, a abertura da atividade regulatória à participação da sociedade nos leva a perceber a institucionalização de novas arenas de atuação de interesses, que buscam influenciar o processo regulatório em direção ao seu benefício. Por conseguinte, o questionamento se mostra premente: a quem beneficiam esses mecanismos de participação?

Para responder tal questionamento, uma análise preliminar dos desenhos institucionais de tais mecanismos se mostra como de fundamental importância. Partindo do pressuposto de que "as instituições importam" para a determinação dos resultados alcançados, analisaremos os principais aspectos institucionais desses mecanismos, tendo em vista a relevância que as "regras do jogo" têm para a definição de, parafraseando Robert Dahl, "quem ganha e quem perde, quando e por quê". Para tanto, partiremos da estrutura proposta por Fung (2006) de classificação de mecanismos de participação.

Fung (2006) estabelece três dimensões que resumem os principais aspectos dos mecanismos de participação: seleção dos participantes, modo de comunicação/decisão dos participantes e extensão do impacto sobre o resultado. A dimensão seleção dos participantes refere-se a quem é qualificado para participar, ou seja, quais são (se há) as restrições impostas para que determinado ator possa participar. A segunda dimensão, modo de comunicação/decisão, refere-se à forma como os participantes interagem com o regulador e entre si e como esses participantes formulam suas opiniões e tomam decisões. Por último, a dimensão extensão do impacto sobre o resultado refere-se à ligação entre o que os participantes propõem e o resultado final da matéria em questão. Abaixo, apresentamos o gráfico que reproduz a estrutura tridimensional do modelo de Fung (2006), mas que, contudo, conta com especificações e categorias próprias, mais adequadas para a problemática e o contexto aqui trabalhados. 
Figura

Modelo tridimensional de desenhos de participação

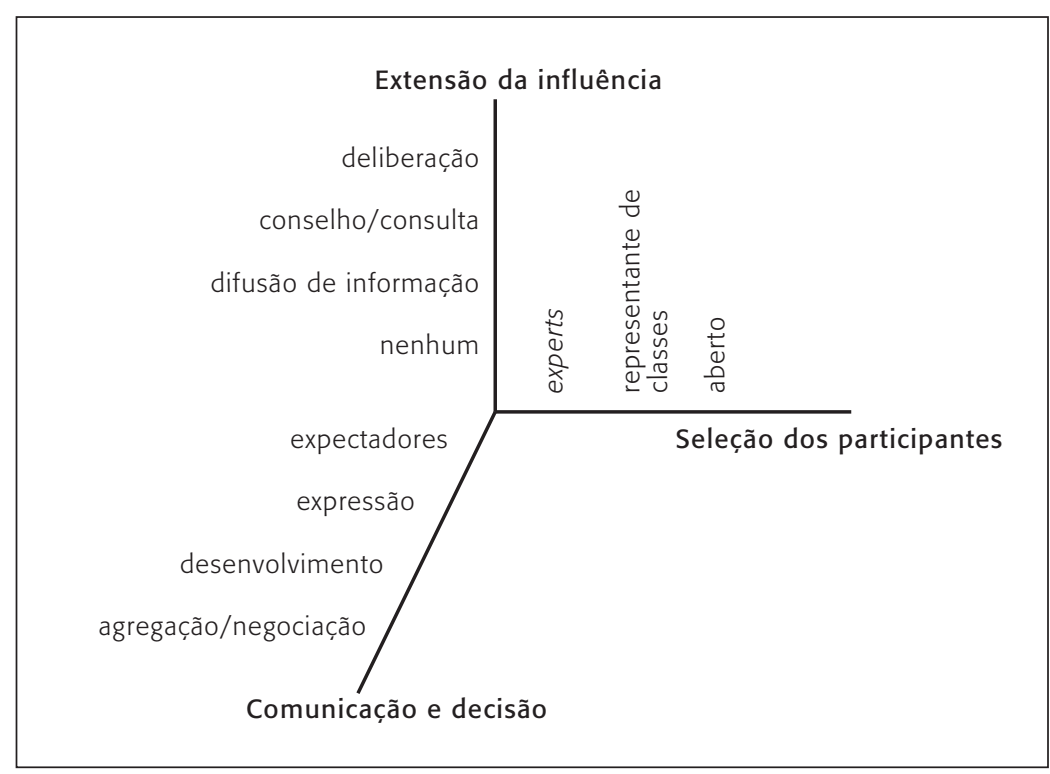

Fonte: Elaboração própria, inspirado em Fung (2006).

A dimensão seleção dos participantes tem por base dois questionamentos centrais: quem é elegível para participar? Como indivíduos se tornam participantes? Tal eixo, ordenado da categoria menos inclusiva para a mais inclusiva, tem como primeira forma de seleção experts, que se caracteriza pelo caráter extremamente exclusivo e formalizado, exigindo dos candidatos alta especialização na área em questão e que, muitas vezes, são instituídos exclusivamente através da indicação. Esse sistema de seleção é visto, principalmente, nas câmaras técnicas, mecanismos de participação que visam à integração de representantes especializados da sociedade. Já a representação de classes se constitui numa forma mais inclusiva, na qual é predeterminada a gama de interesses que poderão se habilitar. Tal forma é comumente vista nos conselhos consultivos, nos quais representantes das principais classes interessadas na política em questão são convidados a integrar um órgão de apoio aos formuladores de decisão. A representação de classes pode tomar uma forma mais ou menos inclusiva, aproximando-se das categorias nos extremos. A forma menos inclusiva é a participação apenas através da indicação e a forma mais inclusiva, aquela que se aproxima do sistema aberto. Neste, qualquer cidadão está habilitado a participar, sendo a forma mais comum das ouvidorias, consultas e audiências públicas.

A dimensão comunicação e decisão é ordenada da forma menos intensa para a mais intensa, intensidade se referindo ao nível de investimento em termos de informação e comprometimento requerido para participar (Fung, 2006). Expectadores se constitui numa forma que efetivamente não envolve nenhum tipo de comunicação ou decisão. A estrutura es- 
tabelecida é a de palestras e exposições, nas quais o participante se torna um mero ouvinte. Já expressão refere-se a uma forma na qual o participante tem a oportunidade de expressar suas preferências. Contudo, tal forma não envolve o debate e a formação e transformação de preferências vistos na forma desenvolvimento. Por último, a forma mais intensa se caracteriza pelo debate contínuo e a modificação de preferências, em busca de uma decisão coletiva. Os conselhos consultivos e câmaras técnicas representam bons exemplos de deliberação. Já as ouvidoras e algumas audiências/consultas públicas se utilizam da forma expectadores, enquanto outros formatos de audiências públicas se vinculam mais ou ao formato expressão ou ao desenvolvimento.

Por último, a dimensão extensão da influência refere-se diretamente ao impacto da participação, à ligação entre o que os participantes expressam e o resultado final. Nenhum se refere à forma na qual o participante não possui expectativa de influenciar o resultado final. Neste sistema, o indivíduo se integra ao mecanismo em busca de benefícios estritamente pessoais, como status ou uma satisfação de um dever cívico (Fung, 2006). Já na forma difusão de informação também não há expectativa de influência direta sobre o resultado final; contudo, a participação em determinados mecanismos gera uma visibilidade que pode, por fim, impactar o resultado indiretamente. Este é o caso da participação de muitos políticos em audiências públicas, nas quais garantem visibilidades para suas posições através da mídia. Na forma conselho/consulta há a possibilidade real de influência sobre o resultado final. Contudo, o regulador ainda reserva para si o direito de aceitar ou não as sugestões advindas dos mecanismos de participação. Este é o caso dos conselhos consultivos e de algumas audiências/consultas públicas. Por último, tem-se o sistema de deliberação, no qual as decisões tomadas efetivamente tornam-se políticas, independentemente da posição do regulador. Tal forma mostra-se mais intensa, porém, de maior dificuldade de aplicação.

As três dimensões desse modelo, em conjunto, proporcionam a possibilidade de classificação dos mais diversos mecanismos de participação social, sendo os elementos enfocados de extrema importância para a análise dos resultados alcançados por determinadas formas de participação. Isto porque a forma como os participantes são selecionados, como se comunicam e tomam decisões e a extensão do impacto de tais decisões orientam diretamente se as preferências dos grupos sociais serão atendidas e quais grupos, especificamente, se beneficiaram e quais não. Para pôr tal modelo em prática e avaliar de forma preliminar seus impactos, analisaremos um mecanismo de participação específico: as audiências públicas da Aneel.

Fundamentamos tal escolha no fato de serem tais audiências espaços de atuação de interesses abertos à sociedade como um todo, nos quais há a efetiva possibilidade de alteração do resultado final e, também, pela transparência de seus procedimentos, por abrir a possibilidade de análise de um fenômeno de difícil mensuração, que é a atuação de grupos de interesse no processo de formulação de políticas.

A escolha da Aneel como unidade de análise baseia-se também no fato de que a energia elétrica se constitui no serviço público de maior alcance na sociedade, afetando todos os segmentos sociais, desde os grupos de interesse mais fortes até os consumidores residenciais. É de grande visibilidade também para o poder público devido ao fato de ser o número total 
de consumidores da mesma proporção do número de eleitores. Portanto, tais audiências se constituem num espaço de articulação e interação entre os mais diversos interesses.

Em termos práticos, duas modalidades de audiências públicas são previstas: a audiência presencial e o intercâmbio documental. No primeiro caso, são previamente marcados data e local, de livre acesso a qualquer cidadão, sendo necessária apenas uma inscrição prévia para a exposição oral. O envio de documentos como contribuições para a matéria em questão também é feito. No segundo caso, apenas a troca de documentos é realizada, não havendo participação presencial nem exposições. Após a realização da audiência (ambos os tipos), a Aneel expede um relatório de análise no qual são divulgadas as contribuições aceitas, as parcialmente aceitas e as rejeitadas.

Tendo em mente essa estrutura geral, passaremos agora, como primeiro passo para a análise aqui proposta dessas audiências públicas, para a exposição dos principais aspectos institucionais desse mecanismo, tendo em vista a importância que as "regras do jogo" têm sobre os resultados alcançados. No caso das audiências públicas da Aneel, o mecanismo atuante de seleção dos participantes é o aberto ou da autosseleção, ou seja, são abertas a qualquer cidadão que deseje participar. Esse mecanismo bastante inclusivo é atenuado pela orientação da Aneel para que os conselhos de consumidores - entidades de representação que envolvem consumidores residenciais, comerciais, industriais, rurais e o poder público, além de um secretário em nome da concessionária - participem das audiências públicas. Esta é uma forma de a Aneel recrutar seletivamente (Fung, 2006) participantes entre grupos de participação menos provável.

No que se refere à dimensão "comunicação e decisão", ao contrário de muitas audiências/consultas públicas, os participantes das audiências públicas da Aneel não são apenas meros espectadores. Eles possuem a oportunidade de expressarem suas opiniões e tomarem decisões que possam vir a influenciar o resultado final. Com relação à interação entre os participantes e à formulação de opiniões por estes, apesar de as audiências promoverem um momento de discussão presencial da matéria em questão, a priori, a formulação de opiniões e decisões é feita externa e isoladamente, e a interação entre os participantes não se dá no sentido de construção de uma opinião comum. Deste modo, o processo de interação e tomada de decisão é mais atomizado e isolado, afastando-se do ideal deliberativo, no qual os cidadãos se empenhariam em, conjuntamente, discutir e tomar decisões acerca de problemas públicos.

Por último, com relação à dimensão "extensão do impacto sobre o resultado", as decisões que os participantes tomam se tornam políticas? Ou estes não têm nenhuma expectativa real de influenciar o resultado final? As audiências públicas da Aneel se posicionam em um meio termo desse continuum, de modo que os participantes, por meio do envio de documentos como contribuição à matéria em questão, têm a perspectiva de influenciar o resultado. Contudo, o regulador, apesar de se comprometer a avaliar e responder aos comentários, mantém a prerrogativa de aceitar ou não as contribuições.

Adicionalmente às três dimensões propostas por Fung (2006), ressaltamos também a gama de matérias que são submetidas ao mecanismo, ou seja, o que é posto em discussão em audiência pública pela agência e com que regularidade? No âmbito da Aneel, o processo deci- 
sório que, mediante projeto de lei ou por via administrativa, afetar os direitos dos produtores ou dos consumidores deve ser precedido de uma audiência pública convocada pela própria agência. Deste modo, uma ampla gama de matérias é submetida ao mecanismo, havendo certa estabilidade, já que sua existência e manutenção são previstas em lei.

A partir do exame dessa estrutura institucional, podemos nos perguntar agora acerca da dinâmica das audiências públicas, tendo em mente os limites e possibilidades impostos pelas "regras do jogo". Isto é, tendo em vista que a participação nessas audiências é regulada pela autosseleção (atenuada pela orientação de participação dos conselhos de consumidores), a tomada de decisão é externa à arena em análise e há a possibilidade efetiva de alteração do resultado final das mais variadas matérias, como os atores se comportam? Ou seja, quem participa? Quem envia contribuições para a matéria em discussão? Quem tem suas contribuições efetivamente aceitas?

Para responder a contento tais questionamentos, é necessário se apoiar em certos pressupostos com relação à lógica de ação dos grupos sociais. Ou seja, uma orientação com relação à razão da participação e de sua eficiência. Na próxima seção nos deteremos nesse ponto.

\section{Interesses no processo regulatório: organização e pressão}

Quando é racional para um indivíduo participar de uma organização? Por que e sob quais circunstâncias é esperado que um grupo de indivíduos se organize e aja em torno de um "interesse coletivo"? Tais questionamentos, centrais para a teoria política, têm seu tratamento teórico mais difundido na obra de Mancur Olson (1999). Refutando a ideia de que a constatação de um interesse comum por um grupo de indivíduos resulta na organização para a promoção desse interesse, Olson argumenta que, apesar de o indivíduo ser beneficiado com uma ação coletiva, ele poderá, racionalmente, não agir para atingir o objetivo coletivo. O elemento central de crítica está na ideia proposta por várias vertentes teóricas de que a ação dos grupos para atingir seus objetivos é uma sequência lógica do comportamento racional dos indivíduos em busca de seus próprios interesses. Nas palavras de Olson (1999:14):

Não é fato que só porque todos os indivíduos de um determinado grupo ganhariam se atingissem seu objetivo grupal eles agirão para atingir esse objetivo, mesmo que todos eles sejam pessoas racionais e centradas nos seus próprios interesses. Na verdade, a menos que o número de indivíduos do grupo seja realmente pequeno, ou ao menos que haja coerção ou algum outro dispositivo especial que faça os indivíduos agirem em interesse próprio, os indivíduos racionais e centrados nos próprios interesses não agirão para atingir seus interesses comuns ou grupais. (...) A noção de que os grupos de indivíduos sempre agirão para promover seus interesses comuns ou grupais, longe de ser uma extensão lógica da premissa de que os indivíduos de um grupo irão racionalmente promover seus interesses individuais, é na verdade incoerente com essa mesma premissa. (destaques no original) 
A explicação para essa dissociação entre interesse próprio e ação coletiva tem por base a lógica própria dos bens públicos. Tendo em vista que os bens públicos por definição são não excludentes, ou seja, quando estão disponíveis para um grupo não podem excluir determinados indivíduos do mesmo grupo de usufruir de seus benefícios, a atitude mais racional para os indivíduos em grupos grandes pode ser não agir para prover tal bem, tendo em vista que ele se beneficiará mesmo não tendo contribuído para a provisão. Deste modo, tendo em vista que a ação coletiva tem por objetivo a provisão de bens comuns, os indivíduos têm grandes incentivos para se portarem como free-riders (caronas), já que podem se beneficiar sem ter o custo de participar, a menos que se trate de um grupo pequeno ou haja algum tipo de coerção ou de benefício seletivo.

No âmbito do debate sobre regulação, a discussão sobre os incentivos para organização e pressão pelos grupos tem como principal expoente as teorias da captura, principalmente a proposta de Stigler, em 1971 (2004). Partindo da ideia da regulação como um produto adquirido por grupos privados, Stigler (2004) modela um sistema de oferta e demanda com base na relação entre grupos de interesse e políticos. Para se manterem no poder, os políticos necessitam de recursos que vão de votos à ajuda financeira. O grupo interessado na regulação necessita de, para dar um exemplo, barreiras à entrada de novos competidores. A relação de oferta e demanda está modelada. Como a regulação favorável prevê uma intervenção no processo político, e esta é bastante custosa, a regulação tende a favorecer os grupos menores, mais diretamente interessados, ou seja, aqueles com maiores grau de organização, informação, que possuam os recursos e estejam dispostos a pagar os custos. Um desdobramento essencial é o de que nem todos os grupos afetados pela regulação se mobilizarão para pressionar por seus interesses, sendo a regulação enviesada em favor dos grupos mais diretamente interessados, principalmente das fortes indústrias, em detrimento dos grupos maiores e consequentemente menos organizados: os consumidores.

O trabalho de Stigler (2004) se constitui na principal referência quando se trata da relação entre regulação e grupos de interesse. Mais especificamente, quando se trata da captura da política regulatória por tais grupos. A importância de postulados como o de que o grupo de produtores é mais apto para "capturar" a política regulatória, por ser esse grupo menor, mais organizado, com mais informação, acesso e recursos, é de inegável poder explicativo. Contudo, ao modelar a relação do jogo da política regulatória como formado basicamente da interação entre políticos e grupos de interesse, essa teoria relega à agência reguladora um papel residual, passivo, de mera implementação da regulação definida na arena política. Desta forma, sua transposição para o problema aqui tratado se mostra problemática, sendo necessária uma argumentação que considere o relacionamento direto entre os grupos de interesse específicos da sociedade e a agência reguladora.

Wilson (1989) nos proporciona tal argumentação ao incorporar os argumentos antes expostos em sua análise de um padrão específico de relacionamento direto entre a estrutura de interesses e a agência. De acordo com sua tipologia, a agência tenderá a beneficiar determinados grupos específicos quando, em suas palavras: 
The benefits have a high per-capita value and the costs have a low per-capita value. Because the recipients' benefits are large, they have an incentive to organize and press for the law; since the costs to those who pay them (per person) are low and perhaps hidden, they have no incentive to organize to oppose the law. (Wilson, 1989:76)

Deste modo, devido à distribuição de custos e benefícios no âmbito da sociedade, a agência tenderá a beneficiar a indústria, que se caracteriza como um grupo pequeno, com menores custos de organização e maiores incentivos para se engajar em ações coletivas, já que os benefícios são concentrados. Já os consumidores, grupos maiores, têm grandes incentivos para não participarem de iniciativas de ação coletiva no sentido de pressionarem contra os custos impostos, devido ao fato de estes serem difusos e os custos de organização e especialização bastante altos.

Com relação aos interesses do regulador e seus incentivos para beneficiar determinado grupo enquanto impõe custos a outro, não necessariamente têm a ver com corrupção. Tal viés pode ter por base tanto a necessidade de informação quanto o poder político que tais grupos possuem.

Dito isto, acreditamos serem os mecanismos de participação social instituídos pelas agências reguladoras importantes arenas a serem analisadas nos termos dos postulados acima traçados. Tendo em mente a estrutura institucional do nosso objeto de estudo, as audiências públicas da Aneel, nas quais a participação é regulada pela autosseleção (atenuada pela orientação de participação dos conselhos de consumidores), a tomada de decisão é externa à arena em análise e há a possibilidade efetiva de alteração do resultado final das mais variadas matérias através do envio de contribuições, partimos da hipótese de que as empresas reguladas serão mais beneficiadas do que os consumidores nesse mecanismo de participação social. Isto porque essas três dimensões institucionais incentivam a participação daqueles mais diretamente interessados e que possuam os recursos necessários para se fazer ouvir pelo regulador. Isto porque o mecanismo institucional de autosseleção dos participantes tem o potencial de fazer com que os mais diretamente interessados se mobilizem para participar. A tomada de decisão externa e isolada entre os grupos resulta no fato de que os custos de especialização tenham de ser arcados pelos próprios grupos, beneficiando aqueles que possuem recursos para arcar com esses custos. Por último, a possibilidade de alteração do resultado final por meio de documentos faz com que a especialização seja fundamental para a efetiva incorporação de seus interesses.

Tendo em mente tais postulados, na próxima seção expomos os principais resultados alcançados.

\section{Resultados}

De modo a alcançar os objetivos propostos neste trabalho, foi realizado um mapeamento de todas as audiências públicas da Aneel, desde 1998, ano de instituição do mecanismo, até as 
audiências do ano de 2006, que foram concluídas em 2007, num total de 233 audiências. Discutimos quem são os participantes, quem envia contribuições e também quem tem suas contribuições efetivamente aceitas. ${ }^{7}$ Os participantes e as colaborações foram classificados tendo por base a nomenclatura utilizada pela própria agência. Já para a abordagem das contribuições enviadas, foram analisados os relatórios de análise expedidos pela agência após a conclusão do processo de audiência pública. Embora não tenham sido elaborados relatórios para todas as 233 audiências, um número bastante expressivo (118) conta com relatórios consolidados, que possibilitam a classificação objetiva de qual participante foi beneficiado e qual não foi. Deste modo, apesar da limitação em número, a escolha pelo foco nos relatórios considerados exime o pesquisador do problema de excesso de subjetividade no momento de classificação dos interesses e do ganho de cada grupo.

Primeiramente, vejamos quem participa e quem envia contribuições.

Tabela 1

Participantes e contribuições por categoria ${ }^{8}$

\begin{tabular}{|ccccc|}
\hline & \multicolumn{2}{c}{ Participantes } & \multicolumn{2}{c|}{ Contribuições } \\
Categoria & Porcentagem & Valor Absoluto & Porcentagem & Valor Absoluto \\
\hline Produtores & $47,31 \%$ & 4400 & $73,47 \%$ & 2335 \\
Consumidores & $22,49 \%$ & 2092 & $8,12 \%$ & 258 \\
Poder Público & $11,40 \%$ & 1060 & $2,93 \%$ & 93 \\
Outros & $14,56 \%$ & 1354 & $11,89 \%$ & 378 \\
Sem Identificação & $4,24 \%$ & 394 & $3,59 \%$ & 114 \\
Total & $100,00 \%$ & 9300 & $100,00 \%$ & 3178 \\
\hline
\end{tabular}

Fonte: Elaboração própria.

Como podemos ver a partir da tabela 1, há uma preponderância de participantes do segmento de interesses regulados pela agência (produtores), correspondendo a 47,31\% de todos os participantes nas audiências, contra 22,49\% de consumidores, $11,40 \%$ do poder público, $14,56 \%$ de outros e 4,24\% sem identificação. Esse fato se explica principalmente pela natureza do setor em questão. A regulação de energia elétrica é um setor que impõe benefícios elevados e concentrados aos agentes e seus custos são de certo modo difusos para a maioria dos consumidores (Wilson, 1989). Isso faz com que os produtores sejam mais incentivados a

\footnotetext{
${ }^{7}$ As informações brutas estão disponibilizadas no site da agência na internet: <www.aneel.gv.br> .

${ }^{8}$ A categoria "produtor" refere-se a qualquer empresa regulada, de geração, transmissão ou comercialização de energia; pública ou privada. Isto porque no setor elétrico ainda existem empresas públicas que com a criação das agências passaram a ser por elas reguladas como uma empresa privada. "Poder público" é uma categoria formada de atores da esfera estatal: Executivo, Legislativo, Judiciário, Ministério Público, Tribunal de Contas. "Outros" é uma categoria heterogênea formada principalmente de pesquisadores, estudantes, ambientalistas e sindicatos.
} 
se organizar e pressionar em defesa de seus interesses e que sofram mais com os problemas de ação coletiva (Olson, 1999).

Com relação aos documentos enviados como sugestão para a matéria em análise, o resultado é ainda mais elucidativo. Do total de contribuições de todas as audiências, 73,47\% são oriundas dos regulados. Apenas 8,12\% são de consumidores. Ficando o poder público, outros e sem identificação, respectivamente, com 2,83\%, 11,89\% e 3,59\%. Os efeitos da distribuição de custos e benefícios discutida são sentidos com ainda mais força, principalmente devido à assimetria de informação e de recursos empenhados pelos agentes na construção dos documentos enviados. Documentos estes de difícil elaboração por um não especialista.

Antes de expor os resultados da análise das contribuições realizada pela agência, momento de maior relevância, já que atesta o efetivo impacto da ação de determinado interesse sobre o resultado final da matéria em questão, enfatizamos a relevância que tal mecanismo tem no âmbito da Aneel, já que todas as matérias submetidas à audiência pública foram modificadas mediante sugestão de algum grupo. Em seguida, expomos a "taxa de efetividade", ou seja, quantas das contribuições enviadas foram atendidas ou efetivamente incorporadas ao documento final.

Tabela 2

Taxa de efetividade das contribuições enviadas ${ }^{9}$

\begin{tabular}{|ccc|}
\hline Resultado Alcançado & Porcentagem & Valor Bruto \\
\hline Aceita Parcialmente & 26,5 & 3039 \\
Aceita & 13,6 & 1564 \\
Rejeitada & 50,3 & 5781 \\
Esclarecimento & 9,6 & 1103 \\
Total & 100 & 11487 \\
\hline
\end{tabular}

Fonte: Elaboração própria.

Como pode ser visto, o número de contribuições efetivamente incorporadas ao documento final é inferior ao número de contribuições rejeitadas. Contudo, revela a real capacidade dos grupos de alterarem o resultado final ao enviarem suas contribuições.

Votando-nos agora para a análise das contribuições por categoria, quais participantes efetivamente influenciam a política regulatória? Quem tem suas reivindicações atendidas?

\footnotetext{
${ }^{9}$ O número total analisado nos relatórios da agência é superior ao de contribuições enviadas porque os relatórios são detalhados, de modo que cada ponto é julgado.
} 
Tabela 3

Análise das contribuições por categoria

\begin{tabular}{|ccccccc|}
\hline $\begin{array}{c}\text { Resultado } \\
\text { Alcançado }\end{array}$ & Produtor & Consumidor & Poder Público & Outros & Sem \\
Identificação & Total \\
\hline Aceita & $26,7 \%$ & $19,9 \%$ & $38,1 \%$ & $15,7 \%$ & $26,9 \%$ & $26,5 \%$ \\
& $(2594)$ & $(126)$ & $(189)$ & $(62)$ & $(68)$ & $(3039)$ \\
Parcialmente & $13,4 \%$ & $15,7 \%$ & $16,7 \%$ & $11,2 \%$ & $12,6 \%$ & $13,6 \%$ \\
Aceita & $(1306)$ & $(99)$ & $(83)$ & $(44)$ & $(32)$ & $(1564)$ \\
Rejeitada & $50,6 \%$ & $50,2 \%$ & $35,3 \%$ & $61,7 \%$ & $51,8 \%$ & $50,3 \%$ \\
& $(4915)$ & $(317)$ & $(175)$ & $(243)$ & $(131)$ & $(5781)$ \\
Esclarecimento & $9,2 \%$ & $14,2 \%$ & $9,9 \%$ & $11,4 \%$ & $8,7 \%$ & $9,6 \%$ \\
& $(897)$ & $(90)$ & $(49)$ & $(45)$ & $(22)$ & $(1103)$ \\
Total & $100 \%$ & $100 \%$ & $100 \%$ & $100 \%$ & $100 \%$ & $100 \%$ \\
& $(9712)$ & $(632)$ & $(496)$ & $(394)$ & $(253)$ & $(11487)$ \\
\hline
\end{tabular}

Fonte: Elaboração própria.

Como podemos ver, os regulados têm $26,7 \%$ de suas contribuições aceitas, ao mesmo tempo que os consumidores têm 19,9\% de suas contribuições aceitas. Tal número demonstra uma sutil sobreposição dos interesses dos regulados. Contudo, neste caso específico, faz-se necessário atentar para os valores brutos, de forma que notamos o fato curioso de que os produtores têm um número gritante diante do número de contribuições aceitas dos consumidores.

A partir desta informação, podemos derivar dois pontos importantes. Primeiro, podemos afirmar que em decorrência dos problemas de ação coletiva, os consumidores têm um número bruto relativamente baixo de proposições aceitas. Contudo, o fato de que a taxa de rejeição dos regulados também é muito alta e que, mesmo tendo-se em consideração o alto número bruto de proposições aceitas, em termos de porcentagem os dois grupos em muito se aproximam, faz-nos ponderar a hipótese pura inicial de que os regulados seriam muito mais beneficiados por esse mecanismo de participação social. Tal constatação nos faz remeter à importância do papel do regulador nesse processo de integração de interesses. Vale ressaltar, também, a alta taxa de contribuições aceitas por representantes do poder público, evidenciando uma articulação não só com a sociedade, mas também com o Estado no âmbito das audiências públicas.

Antes de concluir, acreditamos ser interessante ressaltar algumas reflexões acerca do segmento social intitulado "consumidores", já que tal categoria não é homogênea, podendo esconder diferenças em seu interior.

Podemos desagregar a categoria "consumidores" em três diferentes: os consumidores de grande porte (comercial/industrial), os consumidores de pequeno porte (residenciais) e os conselhos de consumidores. 
Tabela 4

Participantes e contribuições por categoria de consumidor

\begin{tabular}{|ccccc|}
\hline & \multicolumn{2}{c}{ Participantes } & \multicolumn{2}{c|}{ Contribuições } \\
Categoria & Porcentagem & Valor Absoluto & Porcentagem & Valor Absoluto \\
\hline Industriais/Comerciais & $25,5 \%$ & 511 & $69,76 \%$ & 180 \\
Residenciais & $69,16 \%$ & 1386 & $24,41 \%$ & 63 \\
Conselho de Consumidores & $5,34 \%$ & 107 & $5,81 \%$ & 15 \\
Total & $100,00 \%$ & 2004 & $100,00 \%$ & 258 \\
\hline
\end{tabular}

Fonte: Elaboração própria.

Contrariamente ao que seria o esperado, devido aos recursos e incentivos à participação dos consumidores de grande porte, o número de participantes do segmento consumidores residenciais é o preponderante, com $69,16 \%$ do total, contra $25,5 \%$ dos consumidores comerciais/industriais e apenas 5,34\% dos conselhos de consumidores. Resultado inesperado principalmente com relação à diminuta participação dos conselhos de consumidores. Isto porque os conselhos são órgãos consultivos criados, por obrigação legal, pela concessionária de serviço público, especificamente com o objetivo de garantir os interesses dos consumidores. Portanto, é inesperado o fato de não ser sentida a presença desses conselhos que existem num número relativamente alto. Com relação à participação dos consumidores "comerciais/industriais", a explicação consiste no fato de que a participação desse grupo se dá prioritariamente via associação, e não individualmente, como o é pelos consumidores residenciais. Ademais, essa disposição não é repetida com relação às contribuições enviadas. Como podemos observar, a primeira posição se inverte. O número de contribuições dos consumidores comerciais/industriais é muito maior que o dos demais, correspondendo a $69,76 \%$ do total contra $24,41 \%$ dos consumidores residenciais e 5,81\% dos conselhos de consumidores. Isto se dá principalmente devido à necessidade de uma alta expertise para a elaboração desses documentos, dificilmente encontrada num consumidor residencial que não tem os recursos nem os incentivos para a especialização que tem um industrial, já que sua atividade envolve um custo muito mais concentrado. Vejamos agora o aproveitamento de tais contribuições:

Tabela 5

Análise das contribuições por categoria de consumidor

\begin{tabular}{|ccccc|}
\hline & Industrial/ & Conselho de & \\
Resultado Alcançado & Comercial & Residencial & Consumidores & Total \\
\hline Aceita & $20,8 \%$ & $12,5 \%$ & $11,8 \%$ & $19,4 \%$ \\
& $(105)$ & $(1)$ & $(10)$ & $(116)$ \\
Parcialmente Aceita & $11,3 \%$ & $37,5 \%$ & $40 \%$ & $15,7 \%$ \\
& $(57)$ & $(3)$ & $(34)$ & $(94)$ \\
\hline
\end{tabular}

Continua 


\begin{tabular}{|ccccc|}
\hline Resultado Alcançado & $\begin{array}{c}\text { Industrial/ } \\
\text { Comercial }\end{array}$ & Residencial & $\begin{array}{c}\text { Conselho de } \\
\text { Consumidores }\end{array}$ & Total \\
\hline Rejeitada & $50,2 \%$ & $40 \%$ & $48,2 \%$ & $49,9 \%$ \\
& $(254)$ & $(4)$ & $(41)$ & $(299)$ \\
Esclarecimento & $17.8 \%$ & $0 \%$ & $0 \%$ & $15 \%$ \\
& $(90)$ & $(0)$ & $(0)$ & $(90)$ \\
Total & $100 \%$ & $100 \%$ & $100 \%$ & $100 \%$ \\
& $(506)$ & $(8)$ & $(85)$ & $(599)$ \\
\hline
\end{tabular}

Fonte: Elaboração própria.

Analisando a tabela 5, podemos ver que a taxa de sucesso dos consumidores de grande porte é relativamente razoável. Novamente, é importante atentar para os valores brutos. Contudo, um elemento significativo a ser ressaltado é a taxa de sucesso dos conselhos de consumidores (quando consideradas as proposições aceitas e parcialmente aceitas). Isto nos mostra que, apesar da participação e do envio de colaborações relativamente baixo, sua capacidade de alterar o resultado final é maior do que a dos outros grupos, mostrando a importância da iniciativa de organizar os consumidores para que estes possam competir num ambiente de predomínio dos grupos de produtores.

Os dados nos indicam que numa situação de conflito de interesses, a ação de pressionar a agência por um resultado que melhor lhe convenha é mais efetiva quando conduzida pelas empresas reguladas pela agência do que quando conduzida pelos demais segmentos da sociedade. A imposição de benefícios concentrados nos produtores e custos difusos para os consumidores faz com que os benefícios tenham um valor per capita alto, gerando incentivos para os beneficiados (produtores) se organizarem e, contrariamente, os custos tenham um valor per capita baixo e os prejudicados tenham pouco incentivo para pressionarem (Wilson, 1989), implicando um conjunto de incentivos que estimula a ação coletiva no primeiro caso, mas não no segundo. Ambos os segmentos possuem um interesse coletivo, entretanto, o tamanho do grupo se mostra como uma característica fundamental para observar se a busca racional por um interesse comum irá de fato resultar numa ação grupal (Olson, 1999). Contudo, as conclusões a serem derivadas devem ser ponderadas, tendo em vista a taxa comparativamente baixa de contribuições aceitas e a alta taxa de rejeição dos regulados.

Ademais, a análise dos dados nos indica que a estrutura institucional das audiências aqui analisadas representa um espaço de redistribuição de acesso político. No entanto, não promove uma redistribuição do poder e dos recursos (Wilson, 1989). Os limites e também a maior possibilidade dessa iniciativa de controle externo remetem aos mecanismos no desenho institucional capazes de equalizar as diferenças de tamanho e de recursos entre os grupos interessados. A experiência dos conselhos de consumidores, apesar de ainda falha, mostra uma oportunidade para os consumidores. 


\section{Conclusão}

Tivemos por objetivo neste trabalho analisar os interesses envolvidos e quais destes foram beneficiados no mecanismo de participação que são as audiências públicas. A análise da estrutura, dos limites e das possibilidades deste mecanismo teve por foco as audiências da Aneel no período que vai de 1998 até 2006. Tal escolha se deu devido ao fato de ser a energia elétrica um serviço público de enorme alcance na sociedade, afetando vários segmentos sociais, desde os interesses mais desarticulados até os grupos de interesse mais fortes. É de grande visibilidade também para os políticos devido ao fato de o número de consumidores e o de eleitores serem equivalentes. Portanto, tais audiências se constituem num espaço de articulação e interação entre os mais diversos interesses.

A análise dos dados obtidos nos indicou uma sutil sobreposição dos interesses das empresas reguladas pela agência em contraposição aos interesses dos consumidores. Tal fato pode ser explicado a partir da distribuição de custos e benefícios na sociedade que faz com que os benefícios tenham um valor per capita alto, gerando incentivos para os beneficiados (produtores) se organizarem e, contrariamente, os custos tenham um valor per capita baixo e os prejudicados tenham pouco incentivo para pressionarem agindo coletivamente (Wilson, 1989; Olson, 1999).

Um ponto importante refere-se à participação dos conselhos de consumidores. Isto porque a instituição e manutenção desses conselhos, obrigação legal das concessionárias, se constitui no primeiro esforço institucional para diminuir as diferenças de recursos dos consumidores com relação aos produtores. Apesar de ainda ser uma iniciativa incipiente, já mostra alguns resultados positivos em seu objetivo de dotar os consumidores de maior poder diante dos produtores.

Podemos notar também que a estrutura das audiências públicas permite sua consolidação como um "tribunal de julgamento externo" (Noll, 1982), através do qual os diversos grupos da sociedade podem ser "inseridos" no processo regulatório e emitir considerações acerca das ações adotadas, caracterizando uma permeabilidade da atividade regulatória aos interesses da sociedade. Contudo, esforços de desenho institucional devem ser tomados no sentido de prevenir que tal permeabilidade se torne demasiadamente seletiva, beneficiando apenas um grupo em detrimento de outros.

Analisamos aqui a ação dos grupos e também a efetividade da pressão exercida por estes. Entretanto, não objetivamos aqui derivar os resultados a que chegamos com a análise das audiências públicas para o resultado final da política regulatória. Isto porque a regulação se constitui num processo complexo, alvo de pressão de muitos atores, em outras instâncias, internas ou externas, que não as audiências públicas. Assim, esperamos ter contribuído para a incipiente e muito mais ampla área de estudos da relação entre as agências reguladoras e os interesses específicos da sociedade. 


\section{Referências}

ABRANCHES, Sérgio. Reforma regulatória: conceitos, experiências e recomendações. Revista do Serviço Público, ano 50, n. 2, abr./jun. 1999.

ABRÚCIO, Fernando L. Os avanços e dilemas do modelo pós-burocrático: a reforma da administração pública à luz da experiência internacional recente. In: BRESSER-PEREIRA, Luiz C.; SPINK, Peter (Org.). Reforma do Estado e administração pública gerencial. 6. ed. Rio de Janeiro: FGV, 2005.

ANUATTI-NETO, Francisco et al. Os efeitos da privatização sobre o desempenho econômico e financeiro das empresas privatizadas. Revista Brasileira de Economia, v. 59, n. 2, p. 151-175, 2005.

BECKER, Gary. Theory of competition among pressure groups. Quaterly Journal of Economics, V. 98, p. 371-400, 1983.

BRESSER-PEREIRA, Luiz C. Da administração pública burocrática à gerencial. In: BRESSER-PEREIRA, Luiz C.; SPINK, Peter (Org.). Reforma do Estado e administração pública gerencial. 6. ed. Rio de Janeiro: FGV, 2005a.

BRESSER-PEREIRA, Luiz C. Gestão do setor público: estratégia e estrutura. In: BRESSER-PEREIRA, Luiz C.; SPINK, Peter (Org.). Reforma do Estado e administração pública gerencial. 6. ed. Rio de Janeiro: FGV, 2005b.

CORREA, Paulo et al. Regulatory governance in infrastructure industries: assessment and measurement of Brazilian regulators. Washington DC: The World Bank, 2006.

COSTA JUNIOR, Álvaro; SILVA, Rafael. Judicialização das políticas públicas: o caso da regulação do setor de telecomunicações. In: ENCONTRO DA ABCP, 6., Campinas, São Paulo, 2008.

FARIAS, Regina. Controle social na regulação do setor elétrico. Brasília: Tribunal de Contas da União — Instituto Serzedello Corrêa, 2004.

FUNG, Archon. Varieties of participation in complex governance. Public Administration Review, 2006.

GERBER, Brian; TESKE, Paul. Regulatory policymaking in the American states: a review of theories and evidence. Political Research Quarterly, v. 53, n. 4, p. 849-886, 2000.

GOLDEN, Marisa M. Interest groups in the rule-making process: who participates? Whose voice gets heard. Journal of Public Administration Research and Theory, v. 2, 1998.

HOLBURN, Guy; SPILLER, Pablo. Interest group representation in administrative institutions: the impact of consumer advocates and elected commissioners on regulatory policy in the United States. Energy Policy and Economics, n. 2, 2002.

LEVY, B.; SPILLER, Pablo (Org.). Regulations, institutions and commitment. Cambridge: Cambridge University Press, 1996.

LOWI, Theodore. American business, public policy, case-studies, and political theory. World Politics, v. 16, n. 4, 1964. 
MAJONE, Giandomenico. Do Estado positivo ao estado regulador: causa e consequências de mudanças no modo de governança. Revista do Serviço Público, v. 50, n. 1, p. 5-35, 1999.

MATTOS, Paulo (Org.). Regulação econômica e democracia: o debate norte-americano. São Paulo: Editora 34, 2004.

MATTOS, Paulo T.L. The regulatory reform in Brazil: new regulatory decision-making and accountability mechanisms. In: UNIVERSITY OF SAN ANDRES — NEW YORK UNIVERSITY LAW SCHOOL — GLOBAL ADMINISTRATIVE LAW, Buenos Aires, 2007. GAL NYU Law School, 2007.

McCUBBINS, Mathew; NOLL, Roger; WEINGAST, Barry. Administrative procedures as instrument of political control. Journal of Law, Economics and Organization, v. 30, n. 2, p. 243-277, 1987.

MELO, Marcus A. A política da ação regulatória: responsabilização, credibilidade e delegação. Revista Brasileira de Ciências Sociais, v. 46, n. 116, p. 55-68, 2001.

MELO, Marcus A. As agências regulatórias: gênese, desenho institucional e governança. In: ABRUCIO, Fernando; LOUREIRO, Maria R. (Org.). O Estado numa era de reformas: os anos FHC. Brasília: Seges-MP, 2002.

MELO, Marcus A. Política regulatória: uma revisão da literatura. BIB - Revista Brasileira de Informação Bibliográfica em Ciências Sociais, n. 50, p. 7-44, 2000.

MUELLER, Bernardo. Institutions for commitment in the Brazilian regulatory system. The Quarterly Review of Economics and Finance, n. 41, 2002.

MUELLER, Bernardo; PEREIRA, Carlos. Credibility and the design of regulatory agencies in Brazil. Brazilian Journal of Political Economy, v. 22, n. 3, p. 65-88, 2002.

NETO, Floriano. A nova regulação estatal e as agências independentes. In: SUNDFELD, Carlos A. (Org.). Direito administrativo econômico. São Paulo: Malheiros, 2002.

NOLL, Roger. Government regulatory behavior: a multidisciplinary survey and synthesis. Social Science Working Paper. California Institute of Technology, n. 62, p. 1-107, 1982.

NUNES, Edson. O quarto poder: gênese, contexto, perspectivas e controle das agências. In: SEMINÁRIO INTERNACIONAL SOBRE AGÊNCIAS REGULADORAS DE SERVIÇOS PÚBLICOS, II, Brasília, 2001.

NUNES, Edson et al. Agências reguladoras e reforma do Estado no Brasil: inovação e continuidade no sistema político-institucional. Rio de Janeiro: Garamond Universitária, 2007.

OLSON, Mancur. A lógica da ação coletiva. São Paulo: Edusp, 1999.

PACHECO, Regina S. Agências reguladoras no Brasil; Ulisses e as sereias ou Narciso e Eco? In: CONGRESSO INTERNACIONAL DEL CLAD SOBRE LA REFORMA DEL ESTADO Y DE LA ADMINISTRACIÓN PÚBLICA, VII, Panamá, 2003.

PACHECO, Regina S. Regulação no Brasil: desenho das agências e formas de controle. Revista de Administração Pública, v. 40, n. 4, 2006. 
PELTZMAN, Sam. Toward a more general theory of regulation. Journal of Law and Economics, v. 19, n. 2, 1976.

POSNER, Richard. Teorias da regulação econômica. In: MATTOS, P. (Org.). Regulação econômica e democracia - o debate norte-americano. 1. ed. São Paulo: Editora 34, 2004. p. 49-80.

PRESIDÊNCIA DA REPÚBLICA. CÂMARA DA REFORMA DO ESTADO. Plano Diretor da Reforma do Aparelho do Estado. Brasília, 1995.

REZENDE, Flávio. As reformas e as transformações no papel do Estado: Brasil em perspectiva comparada. In: ABRUCIO, Fernando; LOUREIRO Maria R. (Org.). O Estado numa era de reformas: os anos FHC. Brasília: Seges-MP, 2002.

SALISBURY, Robert. Interest representation: the dominance of institutions. The American Political Science Review, v. 78, n. 1, 1984.

SPILLER, Pablo. Institutions and commitment. Industrial and Corporate Change, v. 3, n. 2, p. 421452, 1996.

SPILLER, Pablo. Politicians, interest groups and regulators: a multiple-principals agency theory, or let them "be bribed". Journal of Law and Economics, v. 33, n. 1, p. 65-101, 1990.

SPILLER, Pablo; TOMMASI, Mariano. The institutions of regulation: an application to public utilities. In: MÉNARD, Claude; SHIRLEY, Mary M. (Ed.). Handbook of New Institutional Economics. Berlim: Springer, 2005.

STIGLER, George. A teoria da regulação econômica. In: MATTOS, Paulo (Org.). Regulação econômica e democracia: o debate norte-americano. São Paulo: Editora 34, 2004. [1971]

SUNDFELD, Carlos A. (Org.). Regulação estatal e interesses públicos. São Paulo: Malheiros Editores, 2002.

WILSON, James. Bureaucracy: what government agencies do and why they do it. Nova York: Basic Books, 1989.

Mariana Batista da Silva é doutoranda em ciência política pela Universidade Federal de Pernambuco (UFPE). E-mail: mariana.bsilva@gmail.com. 